\title{
The American Horseshoe Crab (Limulus polyphemus) ${ }^{1}$
}

\author{
Savanna Barry, Holly Abeels, and Shelly Krueger ${ }^{2}$
}

American horseshoe crabs (Limulus polyphemus) are prehistoric-looking creatures that have not changed in appearance since the Mesozoic Era (roughly 200 million years ago) when dinosaurs roamed the Earth. The oldest horseshoe crab fossil dates to 445 million years ago, and their related ancestors are all extinct. For this reason, horseshoe crabs are often referred to as "living fossils."

Despite what the common name implies, horseshoe crabs are not crabs at all. Horseshoe crabs are in the phylum Arthropoda, and within the subphylum Chelicerata. As such, horseshoe crabs are most closely related to sea spiders, spiders, scorpions, ticks, and mites. For context, crabs, shrimp, barnacles, and lobsters are also in the phylum Arthropoda, but these animals are crustaceans. Horseshoe crabs have many jointed legs, and their body is divided into three major parts, which are called the prosoma, the opisthosoma, and the telson. Their body plan is unique, with the mouth located between the bases of their five pairs of jointed legs. They grind the leg bases together to chew and ingest food. They have very good vision, aided by two compound eyes that are capable of seeing objects well both at night and during the day. In addition, they have two median eyes that can sense visible and ultraviolet light on the front area of the shell, the prosoma. They even have light-sensitive eyes underneath the body and on the tail, the telson.
The telson is long and sharp and is often mistaken for a stinger, but the telson is not a stinger. In fact, it is not used in defense at all. Horseshoe crabs use their telson to turn right-side up when they get flipped over by waves or predators. You should never pick a horseshoe crab up by the tail because it can injure the large muscle they rely on to flip back over when they get inverted.

Horseshoe crabs are different from most other invertebrates in that they take a long time to reach maturity-about 10 years on average. Adult horseshoe crabs, often seen nesting on Florida's beaches (Figure 1), are usually at least 9 or 10 years old. Horseshoe crabs molt and shed their shells as they grow larger, and molts (cast-off shells) are often found along Florida's beaches and in tidal flats. You can tell the difference between molted shells and dead crabs by looking to see if there is a slit running along the front. Shells with slits along the front are molts-the animal exits the shell through the slit in the front. Molted shells also appear quite papery and fragile compared to dead horseshoe crabs.

Around the same time horseshoe crabs reach maturity, they undergo a terminal molt, which means they will no longer shed their shells or grow larger. The condition of this final shell degrades as the horseshoe crab ages. You will often see older adult individuals with large barnacles, darkened shells, and deep, pock-like holes in their shells. Individuals with these characteristics are the oldest of horseshoe crabs, nearing their maximum age of approximately 20 years. Younger horseshoe crabs have shells that are smooth, shiny, and lighter in color.

1. This document is SG190, one of a series of the Program in Fisheries and Aquatic Sciences, School of Forest Resources and Conservation, UF/IFAS Extension. Original publication date October 2020. Visit the EDIS website at https://edis.ifas.ufl.edu for the currently supported version of this publication.

2. Savanna Barry, UF/IFAS Extension and Florida Sea Grant regional specialized agent, UF/IFAS Nature Coast Biological Station; Holly Abeels, UF/IFAS Extension and Florida Sea Grant agent, UF/IFAS Extension Brevard County; Shelly Krueger, UF/IFAS Extension and Florida Sea Grant agent, UF/IFAS Extension Monroe County; UF/IFAS Extension, Gainesville, FL 32611.

The Institute of Food and Agricultural Sciences (IFAS) is an Equal Opportunity Institution authorized to provide research, educational information and other services

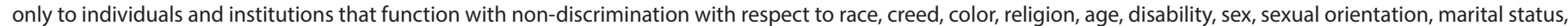

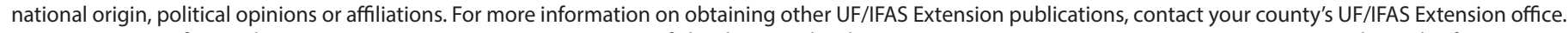
U.S. Department of Agriculture, UF/IFAS Extension Service, University of Florida, IFAS, Florida A \& M University Cooperative Extension Program, and Boards of County Commissioners Cooperating. Nick T. Place, dean for UF/IFAS Extension. 


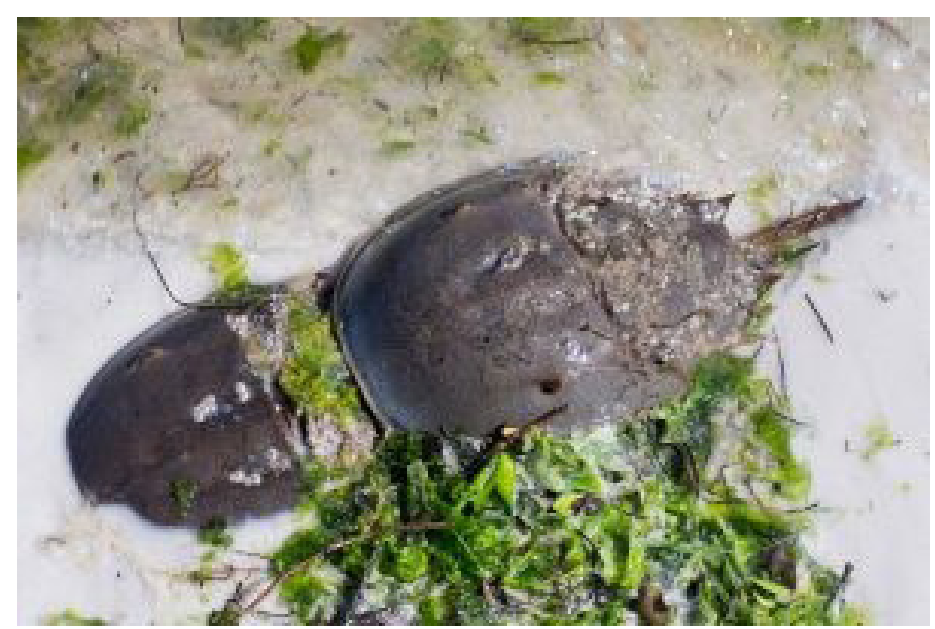

Figure 1. Horseshoe crabs nesting on the beach.

Credits: Tyler Jones, UF/IFAS

\section{The Importance of Horseshoe Crabs}

Horseshoe crabs are ecologically important, especially for shorebirds. Shorebirds such as the endangered red knot depend on the eggs for energy during migration. At least 11 species of migratory birds use horseshoe crab eggs as a food supply during northern migration. Many more marine species, including sea turtles, fish, and crabs, also feed on horseshoe crabs, their eggs, or their larvae.

Horseshoe crabs disturb and aerate the seafloor with plow-like feeding behavior while they search for clams and marine worms. This activity, called bioturbation, enhances species diversity and abundance and oxygenates sediments.

Horseshoe crabs have other values besides ecological ones. In Florida, the primary fishery for horseshoe crabs is actually focused on juveniles that are sold in the aquarium trade. In addition, a smaller number of horseshoe crabs are harvested and used as bait in Florida's eel fishery. This stands in contrast to fisheries in other states, where most of the horseshoe crab take is by the commercial whelk and American eel fishery, and the biomedical industry. While "take" for the eel and whelk fishery means that the horseshoe crabs are harvested in order to be used as bait, in the biomedical industry the horseshoe crabs are released after their blood is harvested.

The biomedical industry uses horseshoe crabs for an important reason. If you have ever received an injection or undergone surgery, horseshoe crabs have helped you. Horseshoe crabs have blue, copper-based blood with blood cells (amebocytes) that contain chemicals that cause the blood to clot when exposed to gram-negative bacteria. These clot-inducing chemicals are harvested from the blood by isolating and breaking open the amebocytes. The chemicals extracted from the amebocytes are then manufactured into the Limulus Amebocyte Lysate (LAL) test. This is a highly sensitive test for the presence of many of the most common and harmful bacteria. The FDA requires that LAL be used to test injectable and intravenous drugs, the medical devices used to deliver these injectable drugs, and on all prosthetic devices (such as hip replacements or heart valves) used in humans and animals. This requirement drives the large demand for wild-collected horseshoe crab blood, though synthetic versions of the LAL test are in development. Horseshoe crabs are collected and taken to a sterile facility, where approximately one third to one half of their blood is extracted. Most of the crabs survive the blood drawing process and are released, although it is estimated that up to $15 \%$ of them die.

In addition to their blood being important in human medicine, chitin, a cellulose-like component from the shell of the horseshoe crab, is used in contact lenses, skin products, and to coat sutures and wound dressings for burn victims. The chitin-coated sutures can improve healing time by $35 \%$ to $50 \%$.

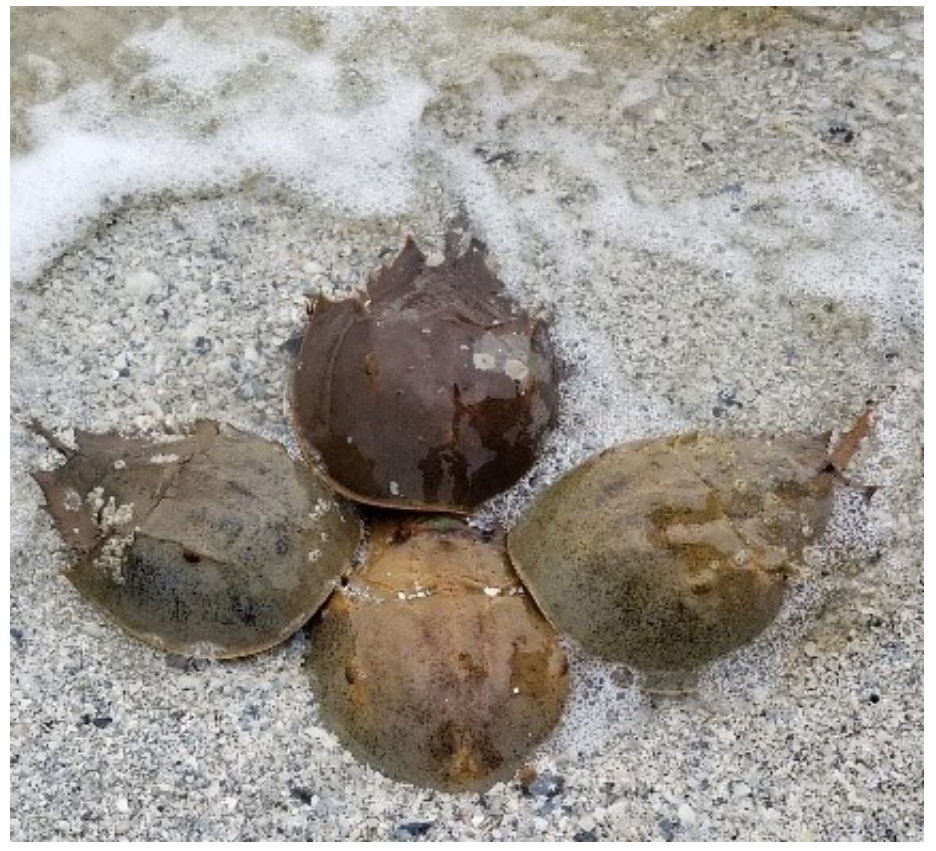

Figure 2. A female horseshoe crab with attached male and two satellite males nesting on the beach.

Credits: Holly Abeels, UF/IFAS

\section{Where do you find horseshoe crabs?}

The American horseshoe crab is found in the western Atlantic Ocean from Maine to Florida, and in the Gulf of Mexico from Florida to Louisiana and along the Yucatan coast of Mexico. There are three additional species of horseshoe crabs, which are all located in Asia. Throughout 
their life, American horseshoe crabs may be found in estuaries and nearshore waters, and they are a common sight in nearshore habitats such as mud flats, marshes, and mangroves. The adults come ashore on sandy beaches to breed, digging nests along the high tide line.

In Florida, horseshoe crabs nest year-round, but peak nesting events are observed in the spring and fall months. Nesting is especially common during extra high tides near the full and new moons, also known as spring tides. They prefer sandy beaches within bays and coves that are protected from intense wave energy. You often see horseshoe crabs coming ashore as attached pairs, where a large female is followed by a smaller male (Figure 2). The male stays attached by clinging to the back of the female's shell using special claws called claspers. You may also see satellite males gathering around attached, nesting pairs. These satellite males are waiting for the female to lay her eggs in the sand so they can fertilize them, too. This mating behavior increases the genetic diversity of the fertilized eggs. The eggs, which are buried in the sand, hatch and emerge from the sand as larvae in about two weeks depending on temperature.

Unfortunately, there have not been consistent, long-term, large-scale, population studies of horseshoe crabs in Florida, so the status of Florida horseshoe crab populations is not well known. Nor do we have basic information about their abundance or movement patterns from one area to another. The Florida Fish and Wildlife Conservation Commission is tasked with managing the horseshoe crab fishery in Florida. The behavior of nesting along shorelines allows researchers to study horseshoe crab breeding populations, counting individuals while simply walking along the shoreline where the animals are nesting. While researchers are counting individuals, they can also collect and tag them for mark-recapture studies.

A volunteer citizen science program called Florida Horseshoe Crab Watch was founded in 2015 to survey and tag breeding horseshoe crabs. This program is a partnership between the Florida Fish and Wildlife Research Institute, UF/IFAS Extension, UF Biology, and Florida Sea Grant. It teaches citizen scientists to collect scientifically accurate information about horseshoe crabs to understand their biology, ecology, and population trends. The data collected by this citizen science effort are used to assist managers in estimating population trends using stock assessment models. In addition, these data provide valuable new information on the biology and ecology of Florida's horseshoe crabs.

\section{How You Can Help Horseshoe Crabs}

Keep your eyes out for tagged horseshoe crabs the next time you are walking the beach. If you see a tagged horseshoe crab, alive or dead, you can help research efforts by reporting the tagged animal. If you find a horseshoe crab stranded upside-down, gently flip it over (by its shell-remember never to grab the crab by its tail) so it can use its legs to return to the water.

To report a tag, follow the instructions in Figure 3. 1) Snap a picture of the tag or record the number on the tag. Try to limit disturbance to the crab. Try not to pick it up, but if you must, never pick it up by the tail. Do not remove the tag unless the crab is dead. 2) Make a note of the date, time, and location where you saw the crab. 3) Report your observations using the online form at https://www.fws.gov/ crabtag or by calling 1-888-546-8587 (1-888-LIMULUS).

Your data will go into a national database maintained by the US Fish and Wildlife Service and contribute to knowledge about horseshoe crab movements and population numbers.

Data from tagged horseshoe crabs in Florida have shown that they can travel at least 110 miles between nesting beaches.

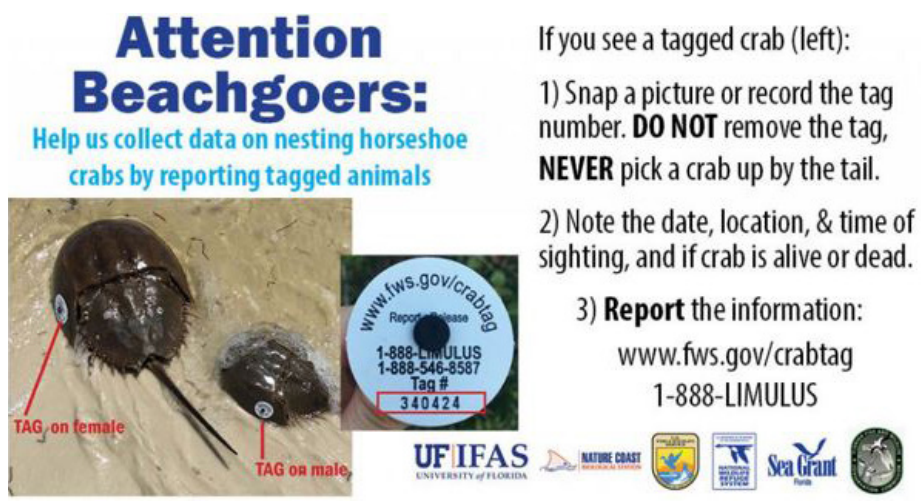

Figure 3. Instructions for reporting a tagged horseshoe crab. Credits: UF/IFAS

\section{To Learn More about Horseshoe Crabs}

Ecological Research \& Development Group, The Horseshoe Crab: http://horseshoecrab.org

Florida Fish and Wildlife Commission, Florida Fish and Wildlife Research Institute: https://myfwc.com/research/ saltwater/crustaceans/horseshoe-crabs/

UF/IFAS Nature Coast Biological Station, Florida Horseshoe Crab Watch: https://ncbs.ifas.ufl.edu/extension/ florida-horseshoe-crab-watch/ 